\title{
Current and Future Heat Stress in Nicaraguan Work Places under a Changing Climate
}

\author{
Perry E. SHEFFIELD ${ }^{1 *}$, Juan Gabriel Ruiz HERRERA ${ }^{2}$, \\ Bruno LEMKE ${ }^{3}$, Tord KJELLSTROM ${ }^{4,5}$ and Luis E. Blanco ROMERO ${ }^{2}$
}

${ }^{1}$ Department of Preventive Medicine, Mount Sinai School of Medicine, USA

${ }^{2}$ Center for Research on Health, Work and Environment (CISTA), Faculty of Medical Sciences, UNAN-León, Nicaragua

${ }^{3}$ School of Health, Nelson Marlborough Institute of Technology, New Zealand

${ }^{4}$ National Centre for Epidemiology and Population Health, Australian National University, Australia

${ }^{5}$ Center for Global Health Research, Umea University, Sweden

Received September 16, 2012 and accepted November 7, 2012

\begin{abstract}
While climate change continues to increase ambient temperatures, the resulting heat stress exposure to workers in non-climate controlled settings is not well characterized, particularly in low and middle income countries. This preliminary report describes current heat stress in Nicaraguan work places and estimates occupational heat stress in 2050. From over 400 measurements of heat exposure using wet bulb globe temperature, more than $10 \%$ of all measurements exceeded the safety threshold for the combination of light work and rest at the ratio of 25:75. By 2050, that percentage of "over-heated" days is projected to increase to over $15 \%$. These findings support the idea that common working conditions in Nicaragua already represent a threat to the health and safety of the workers and that climate change driven trends could mean either a necessary curbing of economic productivity or an increased threat to worker health and safety.
\end{abstract}

Key words: Thermal stress, Work environments, Climate change, Global health, WBGT

While the resources dedicated to elucidating the effects of climate change on human health have grown markedly in the last decade, occupational impacts of climate change remain little explored ${ }^{1)}$. The 'high occupational temperature health and productivity suppression, or HOTHAPS, program ${ }^{2}$ is a multi-center, multi-country effort to document and address the direct effects of increasing heat stress for workers in non-climate controlled settings. Statistics about how many people work in non-climate controlled settings globally are non-existent. However, over one billion people globally are employed in the agricultural sector, second only to the services sector, and

*To whom correspondence should be addressed. Email: perry.sheffield@mssm.edu

(C)2013 National Institute of Occupational Safety and Health within the industrial subsectors there are an estimated 60 million workers from the textile, clothing, and footwear sectors and 20 million people employed in the global chemical, pharmaceutical and rubber and tire industries ${ }^{3)}$. In addition, there are numerous other sectors in manufacturing as well as some service sectors that involve physical demands in high ambient temperature settings. Anecdotal observations reveal that the majority of such settings are not climate controlled indicating that a sizeable proportion of the global population is occupationally heat-exposed.

There are well-established international standards for measuring and regulating heat stress to which workers are exposed. The American Conference of Governmental Industrial Hygienists (ACGIH) and the International Organization for Standardization (ISO) have had established heat stress guidelines and standards for decades ${ }^{4,5}$. 
Comparing estimated temperature increases due to climate change with these guidelines paints a sobering picture for occupational heat stress risk in the coming decades. The Intergovernmental Panel on Climate Change 4th Assessment report estimates an increase of $1.8-4.0^{\circ} \mathrm{C}$ in global average surface temperature by the end of the 21 st century ${ }^{6}$. With a range of just over $7^{\circ} \mathrm{C}$-WBGT between the upper and lower permissible heat exposure thresholds for continuous heavy labor and severely restricted light labor, the climate change-driven trend will likely have major impacts on either worker productivity or their safety, or both. So, while arguably heat-exposed workers are already an area of major importance in terms of global occupational health, the issue is projected to become even more salient in coming years due to the changing global climate.

This project, based in Nicaragua, aims to better characterize the current climate and projected ambient temperature changes as contributors to heat stress in a sample of industrial and service agency settings. Our team obtained the heat stress records from the Nicaraguan Ministry of Labor that included measurements from over 400 different workplace settings representing over 45 distinct companies or agencies. Measurements were taken during multiple seasons between 2008 and 2011 and represent the maximum WBGT conditions as it is standard practice for industrial hygienists to take measurements during the hottest part of the work shift. The metric used to characterize heat stress was wet bulb globe temperature (WBGT) - a reflection of ambient temperature, humidity, and radiative heat sources.

Current heat stress trends were calculated using the Hothaps-Soft database and programming tool ${ }^{7)}$ which uses publically available data from U.S. National Climatic Data Center's Global Surface Summary of the Day ${ }^{8)}$ and applies historic trends to future temperature and heat stress projections. Historic and near real time daily weather data from weather stations in almost every country are available through this website. For Nicaragua, six meteorological stations' data are available. For the purposes of this study, the two stations located in the departments of Managua and Chinandega were used for characterizing the historic and future wet bulb globe temperature. These two were selected because they represented the departments where $90 \%$ of the work setting measurements and the majority of manufacturing activity occurs in the country.

In addition, maps were produced using future estimates from the Climate Research Unit (CRU) at the University of East Anglia (Norwich, United Kingdom) based on the Bergen Climate Model version 2 (BCM2) at grid cell level
$(0.5 \times 0.5$ degrees $)$. The method is described in more detail in another paper in this journal ${ }^{9)}$.

As of 2011, there were approximately 3,000,000 people in the labor force population of Nicaragua with $6.5 \%$ unemployment. The manufacturing and livestock sectors combined made up an estimated $24 \%$ of the annual gross domestic product in 2011 with the agriculture and livestock sector alone constituting $24 \%$ of the employed work force while the manufacturing sector constituted approximately $11 \%$. The number of companies in the manufacturing industry was just over 22,500 out of 121,919 , or $18.5 \%$, of all companies operating in Nicaragua. Of these companies, large, medium, small enterprises respectively constituted $1 \%, 17 \%$, and $82 \%{ }^{10)}$.

Of 441 separate heat stress measurements from 45 distinct companies or agencies, $11 \%$ were in air conditioned settings (Table 1). Excluding those, only $6.7 \%$ of the settings were outdoors with the remaining being in indoor factory or services industry type settings. On the whole, this sample appeared to represent the geographic distribution of companies in Nicaragua with $80 \%$ from the municipal department of Managua, the most densely populated department where the nation's capital by the same name is located. Another almost $10 \%$ of the companies sampled were in the Chinandega department and the remainder in other departments all in the western part of the country consistent with where the vast majority of the population and formal economic sector activities occur. A quarter of the companies sampled were clothing manufacturers of which the majority of those operated in what is called the 'zona franca' or free-trade zone, areas that receive special tax waivers but who manufacture products solely for export, a rapidly growing sector of employment in Nicaragua given recent international trade agreements. The remainder represented an assortment of agricultural and livestock processing plants, plastics manufacturing, pharmaceutical, some university affiliated service sector settings, among others.

In terms of the WBGT for these settings, taken in multiple different months between 2008-2011, the average maximum in all settings combined, including the climate controlled settings, was $27.4{ }^{\circ} \mathrm{C}$. In those without climate control, the average maximum WBGT was $28.4^{\circ} \mathrm{C}$. The highest maximum WBGT recorded in both settings was $38.5^{\circ} \mathrm{C}$. This maximum WBGT was captured in a food processing plant in the department of Chinandega. To put these numbers in context of the Nicaraguan and ACGIH standards (which are the same $)^{4)}, 28.4{ }^{\circ} \mathrm{C}-\mathrm{WBGT}$ would permit light continuous work load; a moderate work load 
Table 1. Workplace and Wet Bulb Globe Temperature (WBGT) characteristics of occupational settings in Nicaragua

\begin{tabular}{lcc}
\hline & All workplaces* $(\mathrm{n}=441)$ & Non-climate controlled workplaces $(\mathrm{n}=405)$ \\
\hline Climate controlled facility (partial or all) & $11 \%$ & $\mathrm{~N} / \mathrm{A}$ \\
Outdoor workplace & $\mathrm{N} / \mathrm{A}$ & $6.7 \%$ \\
Clothing manufacturers** & $31 \%$ & $33 \%$ \\
Average WBGT $\left({ }^{\circ} \mathrm{C}\right)$ & 27.4 & 28.4 \\
Maximum WBGT $\left({ }^{\circ} \mathrm{C}\right)$ & 38.5 & 38.5 \\
$\%$ WBGT $>26.7^{\circ} \mathrm{C}^{* * *}$ & $61.2 \%$ & $66.2 \%$ \\
$\% \mathrm{WBGT}>32.2^{\circ} \mathrm{C}^{* * * *}$ & $10.4 \%$ & $11.4 \%$ \\
\hline
\end{tabular}

*Municipal Department distribution of sample: Managua (80\%); Chinandega (9\%); Carazo (4\%); León (2\%); Masaya (2\%); Matagalpa (2\%). **Most of these operate under special tax-free arrangement with all products being exported. ***Upper limit for continuous work at moderate exertion level per both Nicaraguan norms and ACGIH standards. ****Upper limit for even light exertion for only a $1 / 4$ of every hour, effectively the upper limit for any physical labor, per both Nicaraguan norms and ACGIH standards.

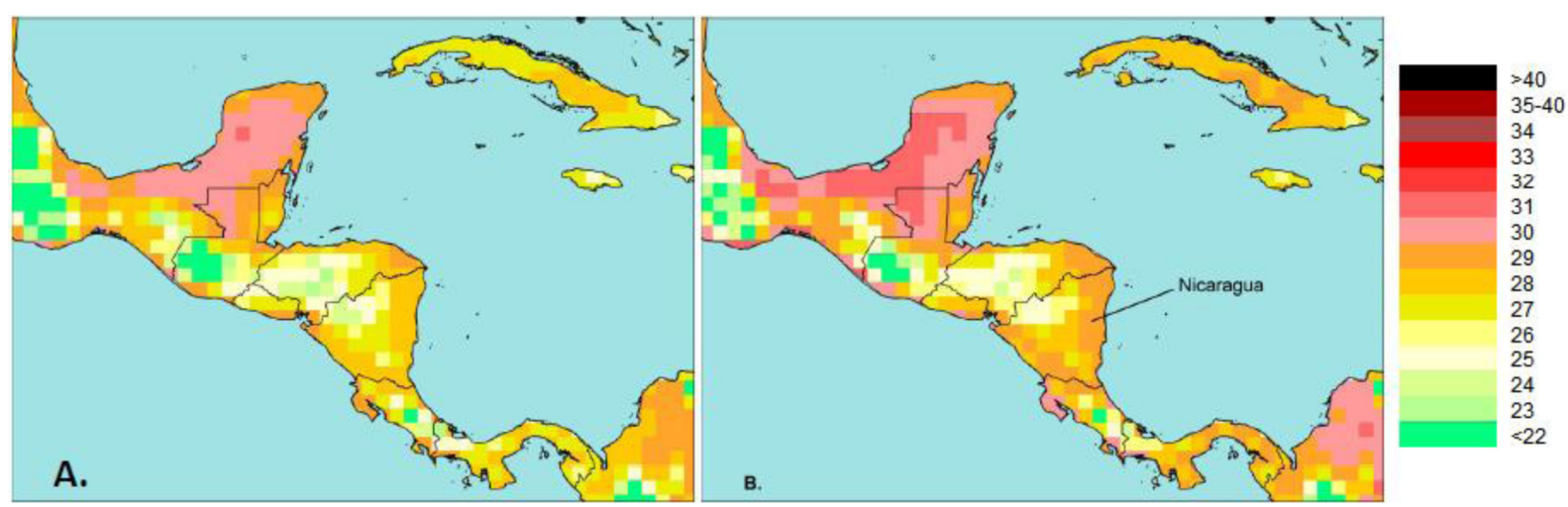

Fig. 1. Estimated Indoor afternoon Wet Bulb Globe Temperature (WBGT, degrees Celsius) in May 2000 (A) and May 2050 projections (B) for Central America and the Caribbean. Outdoor afternoon values can be expected to be 3 degrees Celsius higher.

at 50:50 work: rest ratio; or a heavy work load at 25:75 work: rest ratio. In other words, the average represents a heat stress exposure that should already significantly limit heavy workloads. The maximum WBGT exceeds all threshold value limits, meaning that even light exertion for only a $1 / 4$ of every hour could represent a threat to the health and safety of the workers. In fact, more than $10 \%$ of all WBGT measurements exceeded this upper threshold of $32 .{ }^{\circ} \mathrm{C}$ (Table 1). So even in the present day climate, it is apparent that this tropical country already has significant occupational heat stress.

While direct comparison was not possible, the average maximum WBGT estimates calculated using Hothaps-Soft for the period (1980-2011) overlapping the time period of the measurements obtained from the Nicaraguan Ministry of Labor (2008-2011), showed means of $26.3^{\circ} \mathrm{C}$ WBGT (Managua) and $27.5^{\circ} \mathrm{C}-\mathrm{WBGT}$ (Chinandega), both lower than the Ministry of Labor mean of $28.4{ }^{\circ} \mathrm{C}$ WBGT. The estimates of the maximum WBGT in each of the two regions from Hothaps-Soft were $27.6{ }^{\circ} \mathrm{C}-\mathrm{WBGT}$ and $28.4{ }^{\circ} \mathrm{C}$-WBGT, again lower than the $38.5^{\circ} \mathrm{C}$-WBGT from the Ministry of Labor data. Thus overall, the specific values calculated for a broader time period that overlapped the Ministry of Labor data were all underestimates of the actual measurements. However, another, perhaps more relevant, weather station recorded trends demonstrate that the annual average of daily maximum temperature values have been increasing by $0.21^{\circ} \mathrm{C}$ per decade for the period 1980-2009 in Managua, and $0.27^{\circ} \mathrm{C}$ in Chinandega.

As a whole, the high afternoon WBGTs across Nicaragua are projected to increase approximately $1-2^{\circ} \mathrm{C}$ by 2050 as demonstrated with the example of indoor (or full shade) estimated values for the month of May in Fig. 1. The estimated maximum WBGT for the 30 year climatic period around 2000 was $27.6{ }^{\circ} \mathrm{C}$ in Managua and $28.4{ }^{\circ} \mathrm{C}$ in Chinandega (Table 2), similar to the average WBGT of $28.4^{\circ} \mathrm{C}$ measured in all non-climate controlled settings. The trend projects a WBGT increase of $0.8{ }^{\circ} \mathrm{C}-1.6{ }^{\circ} \mathrm{C}$ 
Table 2. Estimated indoor/or shaded outdoor maximum WBGT in degrees Celsius (without exogenous heat sources)

\begin{tabular}{lcccc}
\hline & $\begin{array}{c}\text { Managua (A.C. Sandino airport) } \\
\text { (Lat 12.15, Long -86.167) }\end{array}$ & $\begin{array}{c}\text { Chinandega } \\
\text { (Lat 12.633, Long -87.133) }\end{array}$ & \% WBGT $>26.7^{\circ} \mathrm{C}^{*}$ & \% WBGT $>32.2^{\circ} \mathrm{C} *$ \\
\hline $1975^{* * *}$ & 27.2 & 28.0 & - & - \\
2000 & 27.6 & 28.4 & $66.2 \%$ & $11.4 \%$ \\
2030 & 28.0 & 28.8 & $73.8 \%$ & $13.1 \%$ \\
2050 & 28.4 & 30.0 & $80.5 \%$ & $15.1 \%$ \\
\hline
\end{tabular}

*See rationale for these threshold selections in Table 1. ** Represents the $30 \mathrm{yr}$ average around each specified year.

in these two departments by 2050 . Using the projected trend for Managua, where $80 \%$ of work place settings were based, future exceedences of indoor (or full shade) values were calculated using the measurements from nonclimate controlled settings. Projected increases from the estimates for periods around 2030 and 2050 were applied to the actual measurements and new percentages that exceeded the threshold were then calculated. By 2050, over $80 \%$ of the maximum WBGT values could exceed the threshold for continuous work at moderate exertion level (a $14 \%$ increase) and over $15 \%$ of the values could exceed the upper limit for even light exertion for only $1 / 4$ of every hour (about a $4 \%$ increase over 2000 values) (Table 2). It should be pointed out that, outdoors in the sun, the afternoon WBGT values are likely to be approximately 3 degrees Celsius higher both in 2000 and $2050^{9 \text { ). }}$.

To summarize these findings, we observed a high percentage of sites with maximum WBGT at levels that require frequent breaks or represent a health and safety risk to workers if the thresholds are not respected. In short, there is already significant heat stress exposure to likely hundreds of thousands of workers in Nicaragua. When considering the impacts that climate change is likely to have in the coming decades, this heat stress exposure is likely to increase, prompting as much as $14 \%$ more of the work place settings to exceed the threshold for continuous work at moderate level.

It is important to note when considering these findings that the heat stress measurements in this study do not account for metabolic workload and nor clothing type of the individual workers. They include only the ambient conditions contributing to the heat stress. However, the measurements from this study are then compared to standards that assume both workload and clothing are considered. Clothing could be assumed to contribute very little to WBGT unless protective clothing is being worn. No data on workers' clothing nor metabolic workload were available from this dataset. In addition, as noted earlier, these measurements were taken for the most part at the hottest part of the work shift as is common practice to try to capture the maximum WBGT. Thus, these values in that regard are an overestimate of the thermal exposure of the workers. Time-weighted averages would be a more accurate measurement of the full work shift exposure.

This type of exploratory characterization study needs to be followed with more specific and individualized examination of workers' heat exposures and their physiologic reactions. Acclimatization of the workers plays a role in what heat stress levels a worker can tolerate. Their acclimatization status needs to be taken into consideration to be able to better understand the potential health impacts. In addition, ultimately, the risk to workers' health will depend on the 'adaptive opportunity' within each work place setting, such as access to cooler resting areas and control over ventilation, as discussed by Parsons ${ }^{4}$. Lastly, actual changes in productivity levels should be explored to both elucidate the potential economic impacts and motivate employers and the government through not only occupational hygiene but also the financial bottom line.

In conclusion, the occupational effects of heat in this low income tropical country are widespread and represent present and increasing threats to worker safety and health as documented by routine monitoring by the Nicaraguan Ministry of Labor and a newly developed software called Hothaps-Soft that uses publically available global meteorologic records to calculate trends and make future projections about worker heat stress exposures.

\section{Acknowledgements}

This work was supported by a 2012-2013 pilot grant from the New York/New Jersey Education and Research Center for Occupational Safety and Health (NIOSH Grant \# T42 OH 008422). The work of Kjellstrom and Lemke was supported by funds at Umea University and the Australian National University. 


\section{References}

1) Kjellstrom T, Holmér I, Lemke B (2009) Workplace heat stress, health and productivity - an increasing challenge for low and middle-income countries during climate change. Glob Health Action 2. [Medline]

2) Kjellstrom T, Gabrysch S, Lemke B, Dear K (2009) The "Hothaps" program for assessment of climate change impacts on occupational health and productivity: an invitation to carry out field studies. Glob Health Action 2 10.3402/gha.v2i0.2082.

3) ILO (International Labor Organization) 2012. Sectoral Activities Department (SECTOR). http://www.ilo.org/ sector/lang-en/index.htm. Accessed August 17, 2012.

4) American Conference of Governmental Industrial Hygienists (2011) TLVs and BEIs: Threshold Limit Values for Chemical Substances and Physical Agents and Biological Exposure Indices. ACGIH, Cincinnati, OH, updated annually.

5) Parsons K (2006) Heat stress standard ISO 7243 and its global application. Ind Health 44, 368-79. [Medline]
[CrossRef]

6) IPCC (2007) Summary for Policymakers. In: Climate Change 2007: The Physical Science Basis. Contribution of Working Group I to the Fourth Assessment Report of the Intergovernmental Panel on Climate Change. Solomon S, Qin D, Manning M, Chen Z, Marquis M, Averyt KB, Tignor $\mathrm{M}$ and Miller HL (Eds.), Cambridge University Press, Cambridge and New York, http://www.ipcc.ch/pdf/ assessment-report/ar4/wg1/ar4-wg1-spm.pdf. Accessed August 18, 2012.

7) Otto M, Lemke B, Kjellstrom T (2013) The Hothaps-Soft software for analysis of climate conditions and trends. Website report at www.climatechip-org (in press).

8) NCDC (2012) National Climatic Data Center Global Surface Summary of the Day. http://www.ncdc.noaa.gov/ cgi-bin/res40.pl?page=gsod.html. August 13, 2012.

9) Kjellstrom T, Lemke B, Otto M (2013) Mapping occupational heat exposure and effects in South-East Asia. Ind Health 51, 56-67.

10) BCN (Banco Central de Nicaragua) 2012. http:www.ben. gob.ni. Accessed July 28, 2012. 